\title{
CARACTERIZAÇÃO DO MICROAMBIENTE EM SECÇÃO TRANSVERSAL DE UM GALPÃO DO TIPO “FREE-STALL" ORIENTADO NA DIREÇÃO NORTE-SUL"
}

\author{
ALESSANDRO T. CAMPOS ${ }^{2}$, ELCIO S. KLOSOWSKI ${ }^{3}$, WALLACY B. R. SANTOS ${ }^{4}$, \\ ELIANE GASPARINO ${ }^{5}$, ALOÍSIO T. CAMPOS ${ }^{6}$
}

\begin{abstract}
RESUMO: O trabalho teve o objetivo de caracterizar o microambiente climático das baias de um galpão de confinamento para gado leiteiro, modelo "free-stall", no sentido transversal da instalação. O "free-stall" é orientado na direção norte-sul, localizado em Marechal Cândido Rondon, região Oeste do Paraná, com capacidade para abrigar 40 vacas em lactação (40 baias). Visando à determinação do Índice de Temperatura do Globo e Umidade (ITGU) e da Carga Térmica de Radiação (CTR), foram instalados quatro globos negros, no centro de baias dispostas no sentido transversal, dispondo dois globos no lado oeste e dois globos no lado leste (separados pelo corredor de alimentação). Lateralmente ao galpão, no lado leste, havia vegetação a $4 \mathrm{~m}$ da instalação, que promovia sombreamento nas primeiras horas do dia. Pode-se concluir que, nas primeiras horas do dia, não há diferença significativa entre os valores de ITGU e CTR encontrados, indicando que o sombreamento, devido à vegetação, foi capaz de amenizar os efeitos da radiação solar. Às $17 \mathrm{~h} 30 \mathrm{~min}$, verificou-se que há ocorrência de maiores valores, tanto de ITGU quanto de CTR, nas baias localizadas no lado oeste do "free-stall".
\end{abstract}

PALAVRAS-CHAVE: ambiência, carga térmica de radiação, gado de leite.

\section{ENVIRONMENT CHARACTERIZATION IN TRANSVERSAL DIRECTION IN A FREE- STALL HOUSING ORIENTED TO NORTH-SOUTH DIRECTION}

SUMMARY: This work aimed to characterize the microclimatic conditions of the stalls of a free-stall model confinement building for dairy cattle in the transversal direction of the installation. Free-stall building was oriented to north-south direction, located in Marechal Cândido Rondon, west of Paraná State -Brazil, with a capacity of 40 dairy cows (40 stalls). In order to determine the Black-GlobeHumidity Index (BGHI) and Radiant Heat Load (RHL), four black globes were installed in the center of stalls disposed in the transversal direction, disposing two globes in the west side and two globes in the east side (separated by the feed alley). At the building sidelong, east side, there was a four meter distant vegetation, that promoted shading in the first hours of the day. With the obtained results, it can be found that, in the first hours of the day there is no significant difference between the results of BGHI and RHL, indicating that the vegetation shading was able to relieve the solar radiation effects. At 17:30 p.m. it was verified the incidence of BGHI and RHL larger values in the stalls located at the free-stall west side.

KEYWORDS: environment, radiant heat load, dairy cattle.

\footnotetext{
${ }^{1}$ Trabalho apresentado no XXXI CONBEA, Salvador - BA.

2 Eng. Agrícola, Prof. Adjunto, Centro de Ciências Agrárias, UNIOESTE, Marechal Cândido Rondon - PR, Fone: (0XX45) 2543216 , e-mail: atcampos@unioeste.br (Coordenador do GPEA - Grupo de Pesquisas em Ambiência do Oeste do Paraná).

${ }^{3}$ Eng. Agrônomo, Prof. Adjunto, Centro de Ciências Agrárias, GPEA/UNIOESTE, Marechal Cândido Rondon - PR.

${ }_{5}^{4}$ Acadêmico de Zootecnia, Centro de Ciências Agrárias, GPEA/UNIOESTE, Marechal Cândido Rondon - PR.

${ }^{5}$ Zootecnista Profa. Adjunta, Centro de Ciências Agrárias, GPEA/UNIOESTE, Marechal Cândido Rondon - PR.

${ }^{6}$ Eng. Agrônomo, Pesquisador da Embrapa Gado de Leite, GPEA, Juiz de Fora - MG.

Recebido pelo Conselho Editorial em: 24-5-2002

Aprovado pelo Conselho Editorial em: 10-11-2003
} 


\section{INTRODUÇÃO}

Os países em desenvolvimento, cada vez mais, adotam o sistema intensivo de produção animal, sendo o confinamento, em galpões modelo "free-stall", um dos preferidos pelos produtores para a criação de gado de leite. Para SILVA (1998), a freqüente situação de altas temperaturas dentro das instalações, geralmente, é devida mais à má concepção e adequação, do que propriamente à adversidade climática. SILVA et al. (1990) expuseram que o mais importante nas instalações é diminuir o balanço de energia entre o animal e o meio, até um limite de otimização, sendo a Carga Térmica de Radiação (CTR) um dos principais componentes do balanço energético de um animal, sendo sua avaliação fundamental no estudo da definição do meio ambiente. De acordo com BACCARI JÚNIOR (1989), o sombreamento pode reduzir de 30 a 50\% a carga de calor sobre os animais.

Segundo BACCARI JÚNIOR (2001), os abrigos devem ser abertos lateralmente, com orientação preferencial leste-oeste no sentido do eixo longitudinal do telhado, principalmente quando as vacas são confinadas nas horas mais quentes do dia. Segundo NÄÄS (2000), os galpões com orientação norte-sul e sombreados podem ser uma solução para evitar a entrada de sol através das laterais das instalações, além de reduzir a CTR incidente.

GARCIA-VAQUERO (1981) argumentou que a orientação das construções é fator intimamente relacionado com o clima do local e que uma boa orientação tem maior importância em alojamentos abertos, onde, além de permitir uma máxima insolação no inverno, deve garantir proteção contra ventos frios dominantes. Segundo KELLY et al. (1950), citados por CAMPOS (1986), em regiões quentes da Califórnia, os abrigos são construídos na direção norte-sul para permitir a entrada de radiação no interior do abrigo o suficiente para secar as urinas e fezes, além de promover melhores condições sanitárias.

Vários índices de conforto térmico têm sido estabelecidos e usados para avaliar o conforto ou desconforto do animal em relação às condições de ambiente. TEIXEIRA (1995) afirmou que o índice de conforto mais usado é o Índice de Temperatura e Umidade (ITU). Porém, para SILVA (2000), esse índice é utilizado para avaliar o ambiente e não demonstra diferenças para animais mantidos em interiores, à sombra ou sob o sol direto. BUFFINGTON et al. (1981) propuseram para vacas leiteiras uma modificação do ITU, que denominaram de Índice de Temperatura do Globo e Umidade (ITGU), como um indicador mais acurado que o ITU, do conforto térmico de vacas expostas a ambientes tropicais.

O presente trabalho teve o objetivo de avaliar a distribuição de temperaturas, por meio do índice de temperatura e umidade e da carga térmica de radiação, em algumas baias de um "free-stall", no sentido transversal de um galpão orientado na direção norte-sul.

\section{MATERIAL E MÉTODOS}

O presente trabalho foi desenvolvido na Granja Schone, localizada na região de Marechal Cândido Rondon, Oeste do Paraná, com 24 33'40" de latitude sul, $54^{\circ} 04^{\prime} 12^{\prime \prime}$ ' de longitude oeste e altitude média de $420 \mathrm{~m}$, no mês de novembro de 2001. O clima da região é subtropical úmido, com precipitação média anual de $1.840 \mathrm{~mm}$, bem distribuídos durante o ano, e temperaturas médias variando entre 14 e $28^{\circ} \mathrm{C}$.

A instalação, objeto do estudo, consiste de um galpão de confinamento, modelo "free-stall", com capacidade para 40 vacas em lactação (com 40 baias), coberto com telhas de cimento amianto, pédireito de $5 \mathrm{~m}$, dotado de lanternim, com sua cumeeira orientada no sentido norte-sul. A região lateral ao galpão, no lado leste, possui sombreamento, a uma distância de $4 \mathrm{~m}$.

Foram instalados globos negros no centro de quatro baias, em fileira, na região central do galpão, com o objetivo de avaliar a distribuição de temperatura no sentido transversal da instalação. Essas 
baias foram protegidas para que os animais não tivessem acesso aos globos. Os globos negros 1 e 2 foram instalados no lado oeste do galpão e os globos 3 e 4 foram instalados opostamente, lado este, separados pelo corredor de alimentação. Dessa forma, os globos 1 e 4 corresponderam às posições "mais externas" do galpão.

Para melhor analisar o conforto térmico no interior da instalação, foram determinados o Índice de Temperatura do Globo e Umidade (ITGU) e a Carga Térmica de Radiação (CTR), conforme eqs.(1), (2) e (3), a seguir:

$$
\mathrm{ITGU}=\mathrm{Tgn}+0,36 \mathrm{Tpo}-330,08
$$

em que,

Tgn - temperatura do globo negro, $\mathrm{K}$, e

Tpo - temperatura do ponto de orvalho, $\mathrm{K}$.

$$
\mathrm{CTR}=\sigma(\mathrm{TRM})^{4}
$$

em que,

CTR - carga térmica de radiação, $\mathrm{W} \mathrm{m}^{-2}$;

TRM - temperatura radiante média, $\mathrm{K}$, e

$\sigma$ - constante de Stefan Boltzmann, 5,67 10 $0^{-8} \mathrm{~K}^{-4}$.

$$
\mathrm{TRM}=100\left\{2,51 \mathrm{v}^{1 / 2}(\operatorname{Tgn}-\mathrm{Ta})+(\operatorname{Tgn} / 100)^{4}\right\}^{1 / 4}
$$

em que,

$\mathrm{v}$ - velocidade do vento, $\mathrm{m} \mathrm{s}^{-1}, \mathrm{e}$

Ta - temperatura do ar, K.

Os ITGUs calculados foram identificados como ITGU1 e ITGU2, correspondentes aos globos negros instalados nas posições 1 e 2, do lado oeste do galpão, e como ITGU3 e ITGU4, correspondentes aos globos negros instalados nas posições 3 e 4, do lado leste do galpão. De maneira análoga, as CTRs foram identificadas como CTR1, CTR2, CTR3 e CTR4, de acordo com a posição dos globos nas baias.

Foram instalados termômetros de máxima e mínima, termômetros de bulbo seco e de bulbo úmido, em abrigo meteorológico, localizado próximo ao galpão. A velocidade do vento foi determinada a partir de anemômetro digital. Os dados foram coletados às $8 \mathrm{~h} 30 \mathrm{~min}, 11 \mathrm{~h} 30 \mathrm{~min}$, 14 h 30 min e 17 h 30 min, considerando o horário real e não o horário de verão (em vigência naquele período).

Para as análises estatísticas, utilizou-se do programa computacional SAEG (1984), considerando como variáveis dependentes o ITGU e a CTR, no modelo em blocos casualizados em um esquema de parcelas subdivididas, sendo as parcelas o posicionamento dos globos nas baias e as subparcelas os horários. As médias foram comparadas por meio do teste de Tukey, adotando-se um nível de significância de $5 \%$ de probabilidade.

\section{RESULTADOS E DISCUSSÃO}

Durante o período avaliado, a temperatura média do ar foi de $26,9{ }^{\circ} \mathrm{C}$; a média das temperaturas máximas foi de $28,8{ }^{\circ} \mathrm{C}$; a média das temperaturas mínimas foi de $20,4{ }^{\circ} \mathrm{C}$; a temperatura máxima absoluta foi de $33,0{ }^{\circ} \mathrm{C}$; a temperatura mínima absoluta foi de $16,0{ }^{\circ} \mathrm{C}$, e a umidade relativa do ar média foi de $63,9 \%$. 
Pela Figura 1 (a), observa-se que, como já esperado, os valores médios diários de ITGU variaram proporcionalmente aos valores médios diários de temperatura do ar e inversamente aos valores médios observados de umidade relativa do ar, sendo que os valores de ITGU, para os quatro posicionamentos, não apresentaram grandes variações entre si. Entretanto, verifica-se na Figura 1 (b) que, para os dias mais quentes (notadamente os dias 1, 2, 5, 6, 9, 10, 12 e 14), os valores de ITGU para os globos nas posições 1 e 2 (lado oeste) diferenciaram-se dos valores obtidos nos posicionamentos 3 e 4 (lado leste).

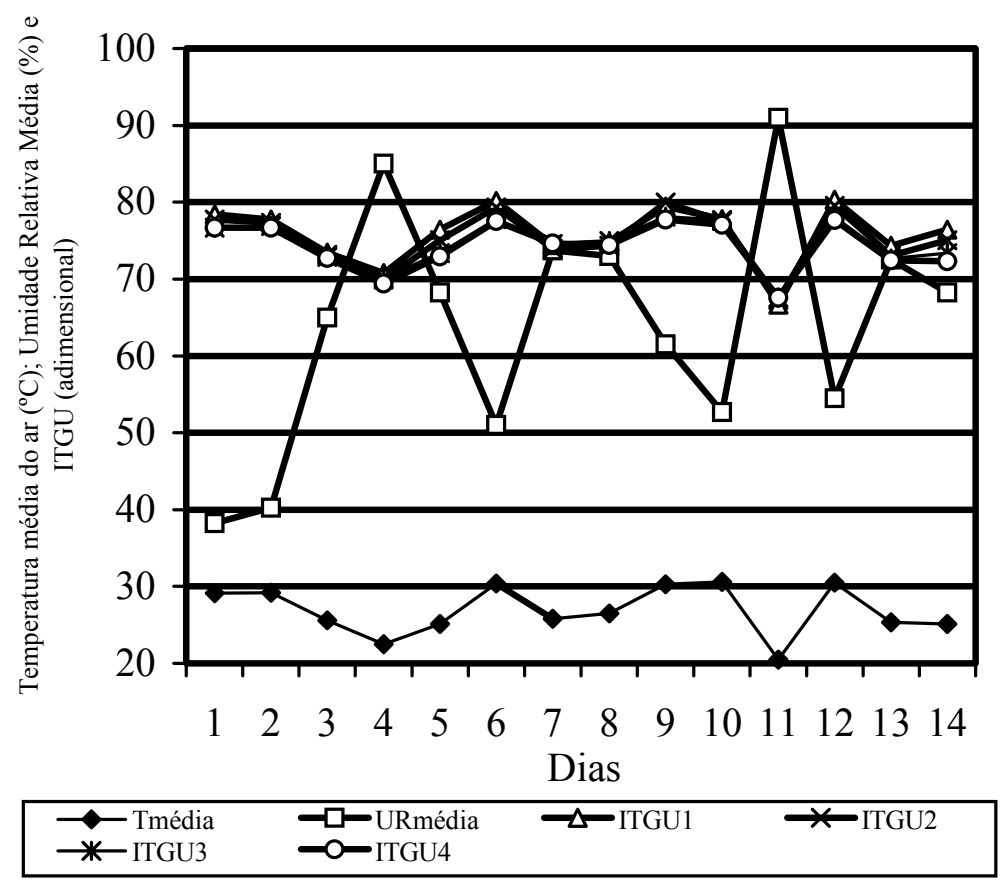

(a)

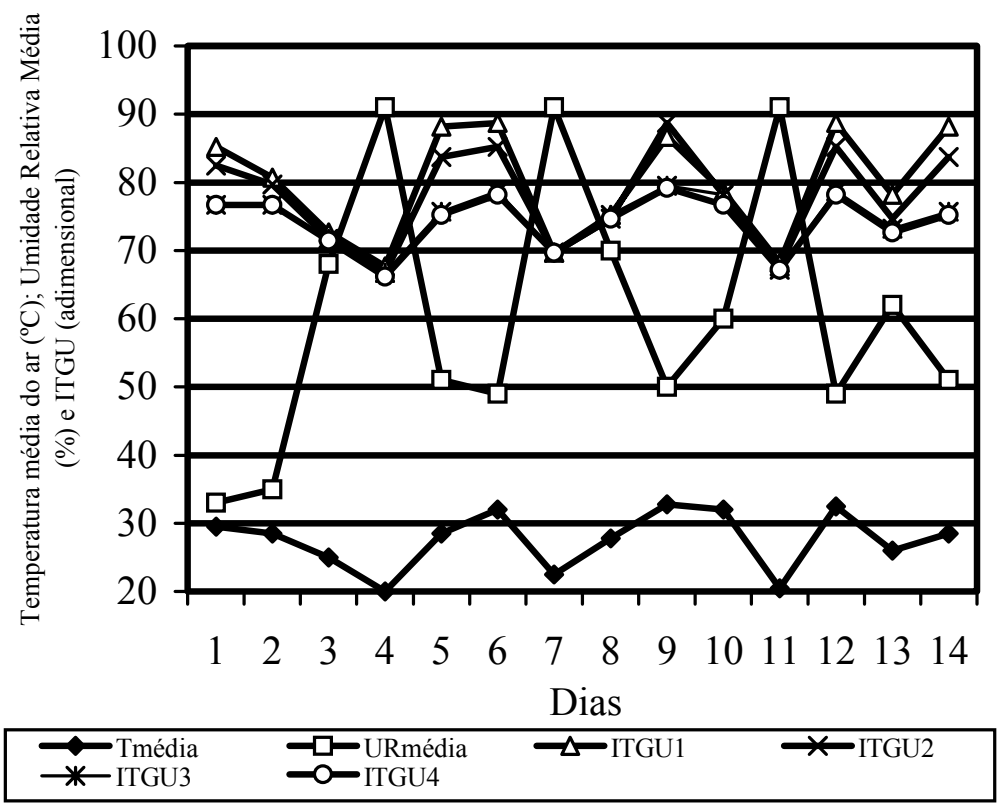

(b)

FIGURA 1. Variação dos valores de ITGU, da temperatura ambiente, e da umidade relativa do ar para dados médios diários (a) e dados diários das 17 h 30 min (b). 
Os resultados médios de ITGU e CTR, durante o período das $8 \mathrm{~h} 30 \mathrm{~min}$ às $17 \mathrm{~h} 30 \mathrm{~min}$, podem ser observados na Figura 2, nos gráficos (a) e (b), respectivamente. Estando o galpão orientado no sentido norte-sul, é normal que incidam raios solares, no nascente e no poente, internamente ao galpão. Entretanto, como se observa na Figura 2 (a), a vegetação situada próximo à face leste do galpão foi eficiente em interceptar os raios solares, sendo que os valores de ITGU, para os quatro posicionamentos de globo, para as $8 \mathrm{~h} 30 \mathrm{~min}$, apresentaram valores em torno de 72 . Os quatro posicionamentos também apresentaram comportamento térmico semelhante às $11 \mathrm{~h} 30 \mathrm{~min}$. No período final da tarde, as posições 2 e 1 (globos no lado oeste do galpão), apresentaram elevados valores de ITGU, 78 e 79,8, respectivamente. Os valores médios da CTR referente ao globo localizado no lado oeste do galpão apresentaram comportamento semelhante aos registrados pelo ITGU; provavelmente devido ao efeito da ventilação, apresentou menores valores no período das $11 \mathrm{~h} 30 \mathrm{~min}$ às $14 \mathrm{~h} 30 \mathrm{~min}$. O posicionamento do globo 1 , na baia mais externa do galpão, sofreu maior influência da radiação solar no período próximo ao ocaso, exibindo um estado de desconforto para essas baias no final da tarde, indicando a necessidade de sombreamento, principalmente nessa lateral do "free-stall", para que os animais possam ocupar as baias ali instaladas em melhores condições de conforto térmico.

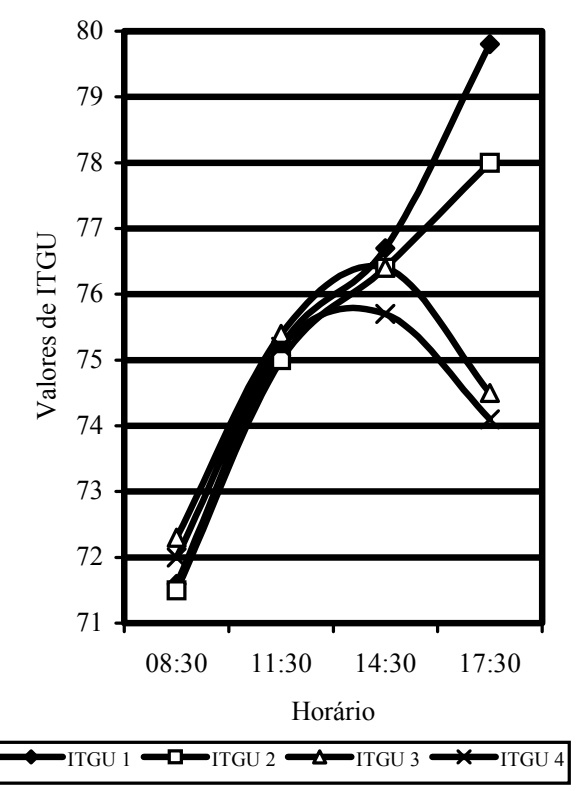

(a)

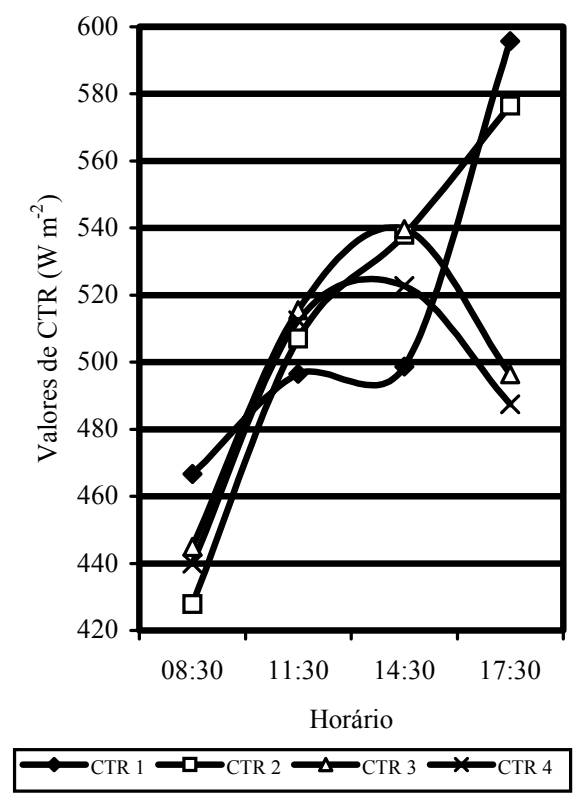

(b)

FIGURA 2. ITGU (a) e CTR (b), durante o dia, para os quatro globos instalados nas baias do "freestall", no sentido transversal do galpão (ITGU1 e ITGU2, CTR1 e CTR2 referem-se aos globos situados no lado oeste do galpão, e ITGU3 e ITGU4, e CTR3 e CTR4 referem-se aos globos situados no lado leste do galpão).

Apesar de os valores de ITGU variarem nos horários e para os diferentes posicionamentos de globos, depreende-se na Tabela 1 que, para os horários das $8 \mathrm{~h} 30 \mathrm{~min}$ às $14 \mathrm{~h} 30 \mathrm{~min}$, não há diferença estatística $(\mathrm{P}<0,05)$ entre os valores de ITGU. Entretanto, às $17 \mathrm{~h} 30 \mathrm{~min}$, para os globos posicionados nas baias do lado oeste (globos 1 e 2), observaram-se maiores valores de ITGU, 79,76 e 78,00 , respectivamente. Estes resultados reafirmam a eficiência do sombreamento utilizando vegetação para amenizar o efeito da radiação solar incidente no lado leste do galpão nas primeiras horas e a necessidade de sombreamento no lado oeste, onde a insolação é mais intensa. Segundo COSTA (1982), o sombreamento promovido por vegetação reduz a incidência da insolação e transforma energia solar, pela fotossíntese, em energia química latente, corroborando a eficiência da vegetação em interceptar a radiação, se comparado a outros métodos de sombreamento exterior. 
TABELA 1. Valores médios de ITGU e CTR em função do horário e posicionamento dos globos nas 4 baias dispostas transversalmente na Instalação

\begin{tabular}{|c|c|c|c|c|}
\hline $\begin{array}{l}\text { Posicionamento } \\
\text { Horário } \\
\end{array}$ & $\begin{array}{c}\text { Globo } 1 \\
\text { (Baia "externa" } \\
\text { lado oeste) }\end{array}$ & $\begin{array}{c}\text { Globo } 2 \\
\text { (Baia "interna" } \\
\text { lado oeste) }\end{array}$ & $\begin{array}{c}\text { Globo } 3 \\
\text { (Baia "interna" } \\
\text { lado leste) }\end{array}$ & $\begin{array}{c}\text { Globo } 4 \\
\text { (Baia "externa" } \\
\text { lado leste) }\end{array}$ \\
\hline \multicolumn{5}{|c|}{ Valores Médios de ITGU } \\
\hline $8 \mathrm{~h} 30 \mathrm{~min}$ & $71,57 \mathrm{a}$ & $71,51 \mathrm{a}$ & 72,27 a & $72,05 \mathrm{a}$ \\
\hline $11 \mathrm{~h} 30 \mathrm{~min}$ & $75,22 \mathrm{a}$ & $75,01 \mathrm{a}$ & 75,38 a & $75,25 \mathrm{a}$ \\
\hline $14 \mathrm{~h} 30 \mathrm{~min}$ & $76,68 \mathrm{a}$ & $76,35 \mathrm{a}$ & 76,43 a & $75,69 \mathrm{a}$ \\
\hline $17 \mathrm{~h} 30 \mathrm{~min}$ & $79,76 \mathrm{a}$ & $78,00 \mathrm{a}$ & $74,53 \mathrm{~b}$ & $74,14 \mathrm{~b}$ \\
\hline \multicolumn{5}{|c|}{ Valores Médios de CTR $\left(\mathrm{W} \mathrm{m}^{-2}\right)$} \\
\hline $8 \mathrm{~h} 30 \mathrm{~min}$ & $466,61 \mathrm{a}$ & $427,86 \mathrm{a}$ & 444,95 a & $439,96 \mathrm{a}$ \\
\hline $11 \mathrm{~h} 30 \mathrm{~min}$ & $496,48 \mathrm{a}$ & $507,09 \mathrm{a}$ & $515,54 \mathrm{a}$ & $512,47 \mathrm{a}$ \\
\hline $14 \mathrm{~h} 30 \mathrm{~min}$ & $498,74 \mathrm{a}$ & $537,94 \mathrm{a}$ & $539,67 \mathrm{a}$ & $522,72 \mathrm{a}$ \\
\hline $17 \mathrm{~h} 30 \mathrm{~min}$ & $595,75 \mathrm{a}$ & $576,51 \mathrm{a}$ & $496,43 \mathrm{~b}$ & $487,48 \mathrm{~b}$ \\
\hline
\end{tabular}

Médias, na linha, seguidas por letras diferentes diferem $(\mathrm{P}<0,05)$ pelo teste de Tukey.

A diferença de valores de ITGU (de 5,62) para as baias situadas em lados opostos, transversalmente no "free-stall", é considerada elevada (ITGUs de 79,76 e 74,14 para as baias onde se situaram os globos 1 e 4, respectivamente, para as $17 \mathrm{~h} 30 \mathrm{~min}$ ). OLIVEIRA (1980), conduzindo pesquisas em Belize, na América Central, em condições tropicais, utilizando construção com orientação norte-sul, concluiu que, no período de verão, houve acréscimo de dois pontos (80 para 82) no ITGU, da área sombreada para a área não sombreada.

Sendo um índice considerado acurado como indicador do conforto e produção animal, BUFFINGTON et al. (1981) verificaram que o ITGU influencia diretamente na temperatura retal e na taxa respiratória de vacas leiteiras, bem como afeta, de forma inversamente proporcional, a produção de leite e a eficiência reprodutiva. BAÊTA (1985) relatou estudos realizados pelo National Weather Service - USA, em que, a partir de 13 anos de observações, constatou que valores de ITGU até 74 definem situação de conforto para os bovinos; de 74 a 78 , situação de alerta; de 79 a 84, situação perigosa, e acima de 84, emergência. Dessa forma, a partir dos resultados apresentados na Tabela 1, depreende-se que, a partir das $11 \mathrm{~h} 30 \mathrm{~min}$, para todas as baias, seria caracterizada uma condição de alerta, com exceção da baia externa localizada no lado oeste, às $17 \mathrm{~h} 30 \mathrm{~min}$, em que se caracterizaria uma situação de perigo, considerando-se essa classificação. Na Flórida, BRAY et al. (1997), citados por BACCARI JÚNIOR (2001), demonstraram que bezerros criados em baias, no interior de um estábulo aberto lateralmente, apresentaram taquipnéia com respiração bucal e alguns chegaram a hipertermia, com ITGU variando de 84 a 91.

À semelhança do ITGU, os valores de CTR variaram, em maior intensidade, às $17 \mathrm{~h} 30 \mathrm{~min}$, $595,75 \mathrm{~W} \mathrm{~m}^{-2}$ para a baia situada no extremo do lado oeste e $487,48 \mathrm{~W} \mathrm{~m}^{-2}$ para a baia situada no extremo do lado leste (diferença de 22\%), como se observa na Tabela 1.

Apesar de haver variação nos valores de ITGU e CTR, entre as duas baias localizadas no lado oeste do galpão (ITGU1 e ITGU2, CTR1 e CTR2), para as 17 h 30 min, como se observa na Figura 1, não houve diferença estatística entre esses valores (Tabela 1).

Assim como consideraram BAÊTA \& SOUZA (1997), é importante salientar que, uma vez que os fatores ambientais são dinâmicos, quando se visa à redução da carga térmica de radiação incidente no interior da edificação onde é conduzida a criação das vacas leiteiras, deve-se projetar a cobertura de acordo com as condições ambientais locais, considerando-se a época do ano e a hora do dia. 


\section{CONCLUSÕES}

No período compreendido entre 8 h 30 min até 15 h 30 min, não há diferença entre o ITGU e a CTR para os lados leste e oeste do galpão.

A instalação orientada na direção norte-sul, recebendo radiação em seu interior na face leste, no período da manhã, teve contribuição da vegetação presente naquele lado para amenizar os efeitos da radiação.

No período do final da tarde, $17 \mathrm{~h} 30 \mathrm{~min}$, houve grande diferença dos valores de ITGU e CTR, tendo as baias localizadas no lado oeste apresentado valores muito maiores que as do lado leste. Não houve diferença estatística entre as baias do mesmo lado da instalação (lado oeste).

Ficou evidenciada a necessidade de sombreamento também no lado oeste da instalação, onde a insolação é intensa no período final da tarde.

De acordo com as características do galpão tipo "free-stall” estudado, a orientação norte-sul também pode ser viável, desde que haja eficiente estrutura de sombreamento nas laterais.

\section{REFERÊNCIAS BIBLIOGRÁFICAS}

BAÊTA, F.C. Responses of lactating dairy cows to the combined effects of tempertature, humidity and wind velocity in the warm season. 1985. $218 \mathrm{f}$. Tese (Doutorado em Ambiência Animal) - Agricultural Engeneering Department, University of Missouri, Columbia, 1985.

BAÊTA, F.C.; SOUZA, C.F. Modificações ambientais. In.: BAÊTA, F.C., SOUZA, C.F. Ambiência em edificações rurais - conforto animal. Viçosa: UFV, 1997. p.187-236.

BACCARI JÚNIOR, F. Manejo ambiental da vaca leiteira em climas quentes. Londrina: Ed. UEL, 2001, 142p.

BACCARI JÚNIOR, F. Manejo ambiental para a produção de leite nos trópicos. In: CICLO INTERNACIONAL DE PALESTRAS SOBRE BIOCLIMATOLOGIA ANIMAL, 1., 1986, Botucatu. Anais... Jaboticabal: FUNEP, 1989. p.45-53.

BUFFINGTON, D.E.; COLLAZO-AROCHO, A.; CANTON, G.H.; PITT, D.; THATCHER, W.W.; COLLIER, R.J. Black-Globe-Humidity Index (BGHI) as comfort equations for dairy cows. Transactions of the ASAE, St. Joseph, v.24, n.3, p.711-14, 1981.

CAMPOS, A.T. Determinação dos índices de conforto e da carga térmica de radiação em quatro tipos de galpões, em condições de verão para Viçosa - MG. 1986. 66 f. Dissertação (Mestrado em Construções Rurais e Ambiência) - Departamento de Engenharia Agrícola, Universidade Federal de Viçosa, Viçosa - MG, 1986.

COSTA, E.C. Arquitetura ecológica - condicionamento térmico natural. São Paulo: Edgard Blücher, 1982. $264 \mathrm{p}$.

GARCIA-VAQUERO, E. Projeto e construção de alojamento para animais. 2.ed. Lisboa: Litexta Portugal, 1981. $237 \mathrm{p}$.

NÄÄS, I.A. Modelos de aviários de frango de corte em termos estruturais e de isolamento. In: SIMPÓSIO BRASILEIRO DE AMBIÊNCIA NA PRODUÇÃO DE FRANGOS DE CORTE EM CLIMA QUENTE, 1., 2000, Maringá. Anais...Maringá: UEM, 2000. p.50-63.

OLIVEIRA, J.L. Hot-weather livestock housing analysis. 1980. 120 f. Tese (Doutorado em Construções Rurais e Ambiência) - Agricultural Engeneering Department, Michigan State University, East Lansing, 1980. 
SISTEMA PARA ANÁLISES ESTATÍSTICAS E GENÉTICAS (SAEG). Viçosa - MG: UFV/CPD, 1984. $94 \mathrm{p}$.

SILVA, I.J.O.; GHELFI FILHO, H.; CONSIGLERO, F.R. Materiais de cobertura para instalações animais. Engenharia Rural, Piracicaba, v.1, n.1, p.51-60, 1990.

SILVA, I.J.O. Climatização das instalações para bovino leiteiro. In: SILVA, IJ.O. (Ed.) Ambiência na produção de leite em clima quente. Piracicaba: FEALQ, 1998. p.114-45.

SILVA, R.G. Índices de adaptação e de conforto térmico. In: SILVA, R.G. Introdução à bioclimatologia animal. São Paulo: Nobel, 2000. p.204-14.

TEIXEIRA, V.H. Resfriamento adiabático evaporativo na edificação de maternidade para suínos. 1995. 101 f. Tese (Doutorado em Energia na Agricultura) - Faculdade de Ciências Agronômicas, Universidade Estadual Paulista, Botucatu, 1995. 